\title{
Corrigendum: Evaluation of the lasso and the elastic net in genome-wide association studies
}

\author{
Patrik Waldmann ${ }^{1,2}$, Gábor Mészáros ${ }^{1}{ }^{*}$, Birgit Gredler $^{3}$, Christian Fuerst $^{4}$ and Johann Sölkner ${ }^{1}$ \\ ${ }^{1}$ Division of Livestock Sciences, Department of Sustainable Agricultural Systems, University of Natural Resources and Life Sciences, Vienna, Austria \\ ${ }^{2}$ Division of Statistics, Department of Computer and Information Science, Linköping University, Linköping, Sweden \\ ${ }^{3}$ Qualitas AG, Zug, Switzerland \\ ${ }^{4}$ ZuchtData EDV-Dienstleistungen GmbH, Vienna, Austria \\ *Correspondence: gabor.meszaros@boku.ac.at
}

Edited and reviewed by:

Henner Simianer, Georg-August University Goettingen, Germany

Keywords: LASSO, elastic net, simulation, GWAS, population structure, cattle

\section{A corrigendum on}

Evaluation of the lasso and the elastic net in genome-wide association studies

by Waldmann, P., Mészáros, G., Gredler, B., Fuerst, C., and Sölkner, J. (2013). Front. Genet. 4:270. doi: 10.3389/fgene. 2013.00270

Translational research program is intended to provide scientists with an incentive to examine research findings from the perspective of concrete applications or other uses, and to give outstanding researchers an opportunity to develop these findings into specific applications and/or economic, societal or social benefits. This program is jointly funded by the Austrian Science Fund (FWF) and the Austrian Ministry for Transport, Innovation and Technology (BMVIT). Therefore, the acknowledgments section of the paper "Evaluation of the lasso and the elastic net in genome-wide association studies" should state:

"The financial support of the Austrian Ministry for Transport, Innovation and Technology (BMVIT) and the Austrian Science Fund (FWF) via the project TRP46-B19 is greatly acknowledged."

Conflict of Interest Statement: The authors declare that the research was conducted in the absence of any commercial or financial relationships that could be construed as a potential conflict of interest.
Received: 16 September 2014; accepted: 17 September 2014; published online: 01 October 2014.

Citation: Waldmann P, Mészáros G, Gredler B, Fuerst $C$ and Sölkner J (2014) Corrigendum: Evaluation of the lasso and the elastic net in genome-wide association studies. Front. Genet. 5:349. doi: 10.3389/fgene. 2014.00349

This article was submitted to Livestock Genomics, a section of the journal Frontiers in Genetics.

Copyright (C) 2014 Waldmann, Mészáros, Gredler, Fuerst and Sölkner. This is an open-access article distributed under the terms of the Creative Commons Attribution License (CC BY). The use, distribution or reproduction in other forums is permitted, provided the original author(s) or licensor are credited and that the original publication in this journal is cited, in accordance with accepted academic practice. No use, distribution or reproduction is permitted which does not comply with these terms. 